\title{
Effect of Salt on the Adsorption Affinity of an Aromatic Carbonyl Molecule to the Air-Aqueous Interface: Insight for Aqueous Environmental Interfaces
}

\author{
Kalyanasis Sahu, ${ }^{\dagger,, \S}$ V. Faye McNeill, ${ }^{*, \dagger}$ and Kenneth B. Eisenthal ${ }^{*, *}$ \\ Department of Chemical Engineering, Columbia University, New York, \\ New York 10027, United States, Department of Chemistry, Columbia University, New York, \\ New York 10027, United States, and Department of Chemistry and Biochemistry, \\ University of South Carolina, Columbia, South Carolina 29208, United States
}

Received: July 30, 2010; Revised Manuscript Received: September 23, 2010

\begin{abstract}
The interface-selective second harmonic generation (SHG) nonlinear optical spectroscopy and the surface tension method have been used to measure the effect of electrolyte on the adsorption isotherm of 4-hydroxyacetophenone (4-HA) at the air-solution interface. It was observed that high $\mathrm{NaCl}$ concentration favors adsorption of organic molecules to the air-solution interface. Measurements of the polarization of the SHG field showed that the orientation of the organic molecule at the air-solution interface is close to that in the neat air-water interface and does not vary with organic concentration. The free energy of adsorption of the molecule to the air-solution interface becomes significantly more negative with an increase in salt concentration, and good agreement was found between the results from the two different techniques. We conclude that the increased affinity of 4-HA for the air-water interface in the presence of $\mathrm{NaCl}$ is due to the salting-out effect.
\end{abstract}

\section{Introduction}

Atmospheric aerosols are typically complex mixtures of inorganic salts and organic molecules. Globally, the most common inorganic salt found in atmospheric aerosols is sodium chloride $(\mathrm{NaCl}) .{ }^{1}$ The organic fraction ranges from simple neutral aromatic and aliphatic hydrocarbons to multifunctional supramolecules such as humic and fulvic acids. ${ }^{2}$ The coexistence of inorganic and organic species at the surface of aqueous atmospheric aerosol particles has a significant impact on the physical and chemical behavior of the aerosol and its effects on atmospheric chemistry and climate. For example, surface organics play an important role in the activation and growth of cloud condensation nuclei by reducing surface tension of the droplet and by acting as a kinetic barrier for the exchange of $\mathrm{H}_{2} \mathrm{O}$ with the gas phase. ${ }^{3-10}$ They also influence the reactive uptake of gases such as $\mathrm{N}_{2} \mathrm{O}_{5}$ from the atmosphere by forming a layer around the aerosol. ${ }^{11-14}$ For these reasons, it is important to understand the effect of salt on the adsorption of organic species to the gas-aqueous interface and how it affects the surface chemistry of aerosol particles.

The presence of salt can either increase or decrease the solubility of organic molecules in water. ${ }^{15-19}$ Strong inorganic salts (e.g., $\mathrm{NaCl}, \mathrm{KCl}, \mathrm{Na}_{2} \mathrm{SO}_{4}$, etc.) decrease the solubility of nonpolar organic compounds, a phenomenon known as saltingout. Large polarizable inorganic salts like lithium perchlorate $\left(\mathrm{LiClO}_{4}\right)$ and most organic salts like butyl ammonium bromide $\left(\mathrm{Bu}_{4} \mathrm{NBr}\right)$ increase the solubility of nonpolar organic molecule (salting-in). ${ }^{15-19}$ The effect of salt also depends on the properties (nonpolar, polar, or ionic) of the organic molecule. ${ }^{15-19}$

\footnotetext{
* To whom correspondence should be addressed. E-mail: vfm2103@ columbia.edu (V.F.M.), kbe1@ columbia.edu (K.B.E.).

${ }^{\dagger}$ Department of Chemical Engineering, Columbia University.

*Department of Chemistry, Columbia University.

${ }^{\S}$ Department of Chemistry and Biochemistry, University of South Carolina.
}

The effect of salt on the adsorption of organic molecules at the air-aqueous interface has been studied by many groups, most commonly using surface tension measurements. ${ }^{20-24}$ These studies have shown that, in general, salts that show salting-out behavior in aqueous solution promote surface adsorption of organic molecules, resulting in lower surface tension. ${ }^{20-24}$ The extent of the salt effect depends on the nature of both the salt and the organic molecule. For example, Goard and Rideal studied the effect of $\mathrm{NaCl}$ on the adsorption of a highly watersoluble molecule, phenol. ${ }^{20}$ They found that, at low salt concentrations, surface tension decreases linearly with increasing salt concentration but at high salt concentrations a plateau is reached. They attributed this behavior to the formation of a monolayer of phenol at an intermediate salt concentration above which multiple layers contribute to the surface tension. ${ }^{20}$ Ozdemir et al. found that in the presence of $\mathrm{NaCl}$ and $\mathrm{KCl}$, sodium dodecyl sulfate (SDS) and methyl isobutyl carbinol (MIBC) become more surface-active than in water. ${ }^{21}$ Donaldson and co-workers investigated the effect of salts $(\mathrm{NaCl}$ and $\left.\left(\mathrm{NH}_{4}\right)_{2} \mathrm{SO}_{4}\right)$ on the adsorption of soluble atmospheric gases (1propanol and hexanoic acid) to the air-water interface. ${ }^{22}$ They found that these salts enhance the surface concentration of the organics for fixed solution concentration but diminish the surface concentration for fixed gas-phase concentration. ${ }^{22}$ Tuckermann et al. measured surface tension of water-soluble organic compounds (WSOC) in water and in the presence of inorganic salts. $^{23,24}$ They found that at high salt concentration, WSOC significantly reduces surface tension of water, which can account for the low surface tension of real cloud and fogwater samples.

The application of surface nonlinear spectroscopy to study the surface partitioning of salts and organic molecules at the air-aqueous interface is also becoming popular due to its unique ability to characterize both composition and the molecular arrangement at the interface. ${ }^{25-36}$ Das and co-workers applied second harmonic generation ( $\mathrm{SHG}$ ) to study the effect of salt on the surface adsorption of $p$-nitrophenol. ${ }^{30}$ They observed that 
the SHG signal of $p$-nitrophenol strongly depends on the type of salt. Lithium chloride ( $\mathrm{LiCl}$ ) enhances (salting-out), whereas lithium perchlorate $\left(\mathrm{LiClO}_{4}\right)$ and guanidinium hydrochloride $(\mathrm{GdmCl})$ reduce (salting-in) surface adsorption of $p$-nitrophenol to the air-water interface. ${ }^{30}$ Vibrational sum-frequecy generation (VSFG) can provide information on both the solute and the solvent (water) at the interface. The adsorption behavior of many neutral and ionic molecules of atmospheric relevance has been studied by VSFG. ${ }^{31-36}$ These studies reveal that the orientation and distribution of molecules at the interface are highly molecule specific. $^{31-36}$

The combination of surface tension measurements with nonlinear optical techniques (VSFG/SHG) may provide new insight into the adsorption behavior of salts and organic molecules at the air-aqueous interface. Adsorption isotherm studies of organic species at the air-electrolyte interface using surface tension are complicated by the fact that inorganic salts such as $\mathrm{NaCl}$ and organic species may have opposite effects on the surface tension of water. As a result, surface tension data are challenging to interpret directly. The nonlinear spectroscopic techniques are sensitive to only the anisotropically ordered layer of molecules at the surface, whereas surface tension is a macroscopic technique and probes an average over an interfacial region (multiple layers). If the layers beyond the top layer are randomly ordered, then the VSFG/SHG signal will originate only from the top layer, but successive layers with lower surface excess will contribute to the surface tension and hence reduce the overall surface excess. ${ }^{31,32} \mathrm{VSFG} / \mathrm{SHG}$ can also provide information regarding the orientation of molecules at the air-solution interface. Both surface tension and VSFG/SHG studies predict negative adsorption of $\mathrm{NaCl}$ from the air-water interface. ${ }^{33,36-38}$ VSFG studies of the Shultz, ${ }^{33}$ Richmond, ${ }^{36}$ and Allen $^{37}$ groups show that $\mathrm{NaCl}$, unlike the polarizable salts $\mathrm{NaBr}$ or NaI, does not alter the vibrational spectra of interfacial water significantly. The very small enhancement of the vibrational spectra observed is attributed to the interfacial depth increase. ${ }^{37}$ This was further supported by the nonresonant SHG study of Wang and co-workers. ${ }^{38}$ Rao et al. differentiated the adsorption behavior of phenol and phenolate at the air-water interface with the aid of surface tension measurements and VSFG. ${ }^{39}$ Richmond and co-workers studied the adsorption of two molecules, dimethyl sulfoxide (DMSO), and methane sulfonic acid (MSA) at the aqueous interface by both VSFG and surface tension. ${ }^{35}$ They found that the square root of the SF intensity is proportional to the surface number density obtained from surface tension measurements for MSA but not for DMSO. They explained the deviation of the result due to the change in orientation and aggregate formation in the case of DMSO as the surface concentration increases. Shultz and co-workers found that in a glycerol-water system, VSFG detects higher surface concentrations of glycerol than from surface tension for the same bulk glycerol concentration. ${ }^{31,32}$ They account for the discrepancy by citing the different probing depth of the interface by the two techniques.

Despite the potential utility of this approach, few groups have applied the combination of surface tension measurements and nonlinear optical techniques to study the effect of salt on the adsorption of organic molecules to the air-water interface. Richmond and co-workers studied the equilibrium and kinetics of the adsorption of hexanoic acid in the presence of $\mathrm{NaCl}$ and $\mathrm{Na}_{2} \mathrm{SO}_{4}{ }^{40}$ They found that the two techniques show different amounts of surface enhancement of hexanoic acid in the presence of salt. This was attributed to a change in the orientation and aggregation of hexanoic acid at the interface in

\section{SCHEME 1: 4-Hydroxyacetophenone (4-HA)}

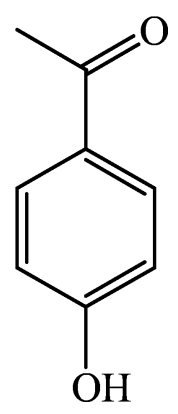

the presence of salt. ${ }^{40}$ The adsorption behavior of a long-chain ionic molecule may be complicated by the electrostatic interaction between ionic headgroups or with the electrolyte ions and aggregate formation of the hydrophobic tails at the interface.

In this study, we examine the link between salting-out phenomena and adsorption of 4-hydroxyacetophenone (4-HA, Scheme 1) to the air-aqueous interface. 4-HA is a moderately soluble neutral molecule that is structurally similar to atmospherically important compounds: phenol and aromatic molecules containing a carbonyl $(>\mathrm{C}=\mathrm{O})$ group. 4-HA has been detected in organic aerosols formed from the photo-oxidation of aromatic species. ${ }^{41}$ 4-HA has a bulk $\mathrm{p} K_{\mathrm{a}}$ of $\sim 8 .^{42}$ Surface $\mathrm{p} K_{\mathrm{a}}$ values of phenolic molecules are usually higher than the bulk $\mathrm{pH} .{ }^{43}$ Hence, we anticipate that 4-HA will mostly be present at the air-water interface in undissociated form at a neutral $\mathrm{pH}$. We investigated effects of high concentrations of $\mathrm{NaCl}(2.8$ and $4.5 \mathrm{M}$ ), such as may be encountered in environmental systems, on the affinity of 4-HA to the air-water interface by both surface tension and second harmonic generation. $\mathrm{NaCl}$ was observed to significantly decrease the free energy of adsorption of 4-HA to the air-aqueous interface. The results from surface tension measurements and SHG are in good agreement, suggesting that interactions between 4-HA molecules at the surface are neglible under these conditions. We conclude that the bulk salting-out effect is the controlling factor in the enrichment of 4-HA at the air-water interface.

\section{Experimental Section}

4-Hydroxyacetophenone (99\%) and sodium chloride ( $\geq 99.5 \%)$ were purchased from Sigma-Aldrich Chemicals and were used as received. Samples were prepared just before experiment. Aqueous solutions were prepared using water from a $18 \mathrm{M} \Omega$ nanopure system. All surface tension and SHG measurements were carried out at 22 and $18{ }^{\circ} \mathrm{C}$, respectively.

Surface tension was measured by the Wilhelmy plate method. For each sample, three replicate measurements were made and averaged values were used for calculation. Each sample was allowed to equilibrate for $30 \mathrm{~min}$ before the measurement.

The laser setup for SHG experiments consisted of a Nd: $\mathrm{YVO}_{4}$ solid-state laser (Spectra-physics, Millenia Vs) pumped Ti: sapphire laser (KMLab), which provides 50 fs pulses at 834 $\mathrm{nm}$. The fundamental beam with energy of $2 \mathrm{~nJ}$ per pulse was focused on the sample interface at $70^{\circ}$ from surface normal. Polarization of the beam was controlled by a half wave plate and a polarizer. A red filter is used before the sample to cut off any possible second harmonic generated by the fundamental laser impinging on optical components before it reaches the interface. The fundamental beam reflected from the interface was eliminated using a blue pass filter. The signal at the second harmonic wavelength $(417 \mathrm{~nm})$ was selected by a monochromator (CVI Digikrom 240). An analyzer was used to select the 


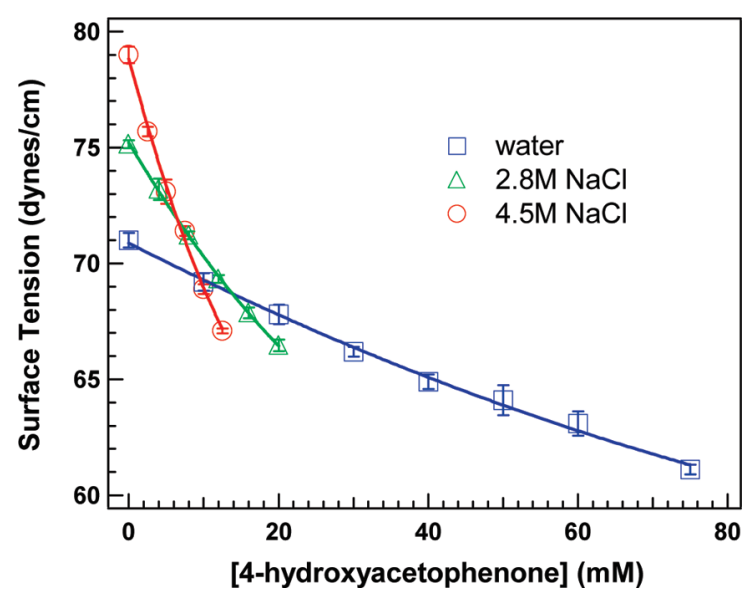

Figure 1. Plot of surface tension against concentration of 4-hydroxyacetophenone in water $(\square), 2.8 \mathrm{M} \mathrm{NaCl}(\triangle)$, and $4.5 \mathrm{M} \mathrm{NaCl}(O)$ solutions. Points represent experimentally observed values and the lines represent polynomial fit to the data.

appropriate polarization of the SHG signal. We used a PMT (Hamamatsu R4220P) and a single photon counter to measure the SHG signal. For the SHG isotherm measurements, the input polarization was fixed at $45^{\circ}$ with respect to the incident plane and the s-polarized signal was detected. To measure the null angle, the analyzer was rotated to get the lowest signal keeping the input polarization at $45^{\circ}$. The sample dish was placed on a rotating stage (Newport ESP 100 Universal motion controller/ driver) to minimize local heating of the sample.

\section{Results and Discussion}

Surface Tension Measurements. The presence of organic species at the air-water interface is manifested by the lowering of the surface tension of water (Figure 1). The higher adsorption affinity is manifested in a steeper slope in the surface tension plot against concentration of the organic molecule. From Figure 1 , it is evident that surface tension decreases more dramatically at high salt concentrations. Note that the surface tension isotherms of 2.8 and $4.5 \mathrm{M} \mathrm{NaCl}$ start from higher values, which is due to the fact that $\mathrm{NaCl}$ increases the surface tension of water. On the other hand, organic adsorbates reduce the surface tension of water. As a result, the surface tension of a solution containing both inorganic and organic solutes depends markedly on the composition of the mixture. At a low bulk organic concentration, surface tension increases with increasing salt concentration. However, at high bulk organic concentrations, the surface tension of the solution decreases with an increase in the salt concentration.

Surface tension data were fitted to a polynomial function and the surface excess $(\Gamma)$ of 4-HA at the interface was calculated according to the Gibbs adsorption equation. ${ }^{44}$

$$
\Gamma=-\frac{a}{R T} \frac{d \gamma}{d a}
$$

where $a$ is the activity of the 4-HA. The dilute 4 HA solutions here are assumed to be ideal, thus activity is replaced by the bulk concentration of the 4-HA. Part a of Figure 2 shows the surface excess of 4-HA in water and aqueous solutions containing $2.8 \mathrm{M} \mathrm{NaCl}$ or $4.5 \mathrm{M} \mathrm{NaCl}$ at different organic concentrations. It is clear from the plot that, for same bulk concentration of 4-HA, the surface concentration of 4-HA increases with increasing $\mathrm{NaCl}$ concentration. For example, at a bulk 4-HA concentration of $10 \mathrm{mM}$, the surface excess of 4-HA at the air-solution interface of the $2.8 \mathrm{M} \mathrm{NaCl}$ solution is $\sim 3$ times higher than that at the air-pure water interface and $\sim 5$ times higher for $4.5 \mathrm{M} \mathrm{NaCl}$ solution. A plot of the surface excess, $\Gamma$, of 4-HA as a function of its bulk concentration, $c$, at a fixed $\mathrm{NaCl}$ concentration can be fit with the Langmuir adsorption isotherm: ${ }^{44}$

$$
\Gamma=\frac{\Gamma_{\max } c}{c+a}
$$

where the fit parameter $\Gamma_{\max }$ represents the limiting (saturation) surface excess and the fitted values are $3.3 \pm 0.2 \times 10^{14}, 3.6 \pm$ $0.2 \times 10^{14}$, and $3.8 \pm 0.3 \times 10^{14}$ molecules $\mathrm{cm}^{-2}$ respectively for water, $2.8 \mathrm{M} \mathrm{NaCl}$, and $4.5 \mathrm{M} \mathrm{NaCl}$. Theses values are $\sim 2$ times higher than the maximum experimentally observed surface excess (part a of Figure 2), which means even at the highest bulk concentration of 4-HA, roughly half of the surface sites are filled. The parameter $a$ is related to the Gibbs free energy of adsorption $(\Delta G)$ according to: ${ }^{44}$

$$
\Delta G=R T \ln (a / 55.5)
$$

The calculated free energies are summarized in Table 1. Upon addition of $\mathrm{NaCl}$, the adsorption free energy of 4-HA decreases
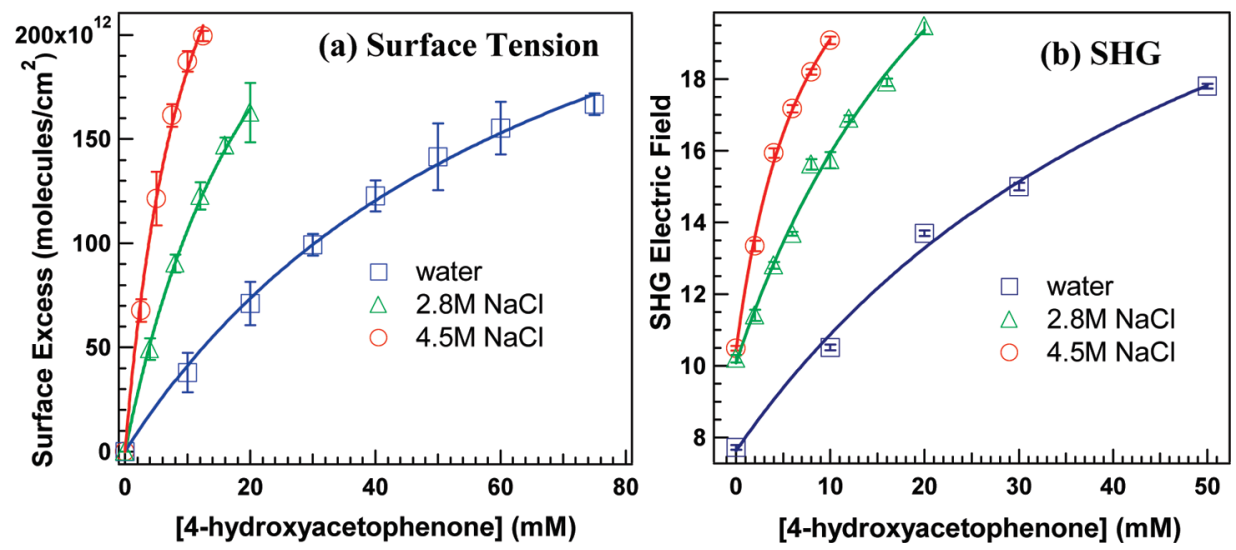

Figure 2. (a) Surface excess of 4-hydroxyacetophenone against the bulk concentration of 4-hydroxyacetophenone in water ( $\square$ ), $2.8 \mathrm{M} \mathrm{NaCl}(\triangle)$, and $4.5 \mathrm{M} \mathrm{NaCl}(\mathrm{O})$ at $22{ }^{\circ} \mathrm{C}$. (b) Second harmonic isotherm of 4-hydroxyacetophenone in water $(\square), 2.8 \mathrm{M} \mathrm{NaCl}(\triangle)$, and $4.5 \mathrm{M} \mathrm{NaCl}(\mathrm{O})$ at 18 ${ }^{\circ} \mathrm{C}$. Curves represent Langmuir fits to the data according to eq 2 (panel a) and eq 4 (panel b). 
TABLE 1: Free Energy of Adsorption and Salting Coefficient of 4-Hydroxyacetophenone from Surface Tension and Second Harmonic Generation

\begin{tabular}{lcclcc}
\hline & \multicolumn{2}{c}{ surface tension } & & \multicolumn{2}{c}{ SHG } \\
\cline { 2 - 3 } system & $\Delta G(\mathrm{kcal} / \mathrm{mol})$ & $k_{\mathrm{s}}$ & & $\Delta G(\mathrm{kcal} / \mathrm{mol})$ & $k_{\mathrm{s}}$ \\
\hline water & $-3.9 \pm 0.06$ & & & $-4.0 \pm 0.2$ & \\
$2.8 \mathrm{M} \mathrm{NaCl}$ & $-4.5 \pm 0.05$ & $0.15 \pm 0.03$ & & $-4.4 \pm 0.2$ & $0.10 \pm 0.08$ \\
$4.5 \mathrm{M} \mathrm{NaCl}$ & $-5.0 \pm 0.08$ & $0.17 \pm 0.2$ & & $-5.1 \pm 0.1$ & $0.18 \pm 0.04$
\end{tabular}

from $-3.9 \pm 0.06 \mathrm{kcal} / \mathrm{mol}$ in water to $-5.0 \pm 0.08 \mathrm{kcal} / \mathrm{mol}$ in $4.5 \mathrm{M} \mathrm{NaCl}$ (Table 1).

Second Harmonic Generation. Nonresonant SHG signal $\left(I_{\mathrm{SHG}}\right.$ ) contains contributions from all of the species (water, $\mathrm{NaCl}$, and the solute) present at the air-water interface. The SHG electric field $\left(E_{\mathrm{SHG}}=\sqrt{ } I_{\mathrm{SHG}}\right)$ can be expressed as $E_{\mathrm{SHG}} \propto\left(\chi^{(2)}{ }_{\text {water }}\right.$ $\left.+\chi^{(2)} \mathrm{NaCl}+\chi_{\mathrm{s}}^{(2)}\right) E_{\omega} E_{\omega}$, where $E_{\omega}$ is the amplitude of the incident light at frequency $\omega$. For the adsorption isotherm measurement, the concentration of the organic molecule (4-HA) was varied and the signal of the organic molecule can be easily discernible from the constant background $\mathrm{SHG}$ due to water and $\mathrm{NaCl}$ (part $\mathrm{b}$ of Figure 2). The second-order susceptibility of the organic molecule $\chi_{\mathrm{s}}{ }^{(2)}\left(=\mathrm{N}_{\mathrm{s}}\langle\beta\rangle\right)$ depends on the number of surface molecules $\left(N_{\mathrm{s}}\right)$ and the orientation averaged second-order nonlinear polarizibility $(\langle\beta\rangle){ }^{25-27} \mathrm{~A}$ simple polarization null angle measurement of the SHG light can show whether orientational parameters (orientation angle and angular distribution) remain the same or change upon the addition of the organic molecule; however, accurate determination of the orientational parameters requires more detailed analysis. ${ }^{28,29}$ As the measured null angles were invariant, we infer that a change in the orientational parameters is not the dominant factor contributing to the observed signal increment when the concentration of 4-HA was varied in water or in aqueous $\mathrm{NaCl}$ solution (Figure 3 ). Hence, the second harmonic electric field enhancement is directly proportional to the surface number density of the adsorbed organic molecule. Note that the second harmonic signal of the electrolyte solution interface is higher than that of the water interface in the absence of 4-HA (part b of Figure 2). This was explained by Wang and co-workers ${ }^{38}$ as an increase of the interfacial thickness of water layer in the presence of salt. For the same bulk concentration of the organic, the second harmonic signal increases as the concentration of salt increases, indicating that more organic molecules are present at the air/ solution interface at higher salt concentrations. Recognizing that the SHG signal is proportional to surface excess, the SHG data can be fit using a modified Langmuir adsorption isotherm as follows:

$$
E_{\mathrm{SHG}}=\frac{E_{\mathrm{SHG}, \max } c}{c+a}+E_{0}
$$

In eq 4 , we replace the surface excess with the total SHG field and add a constant $E_{0}$ that constitutes the background SHG
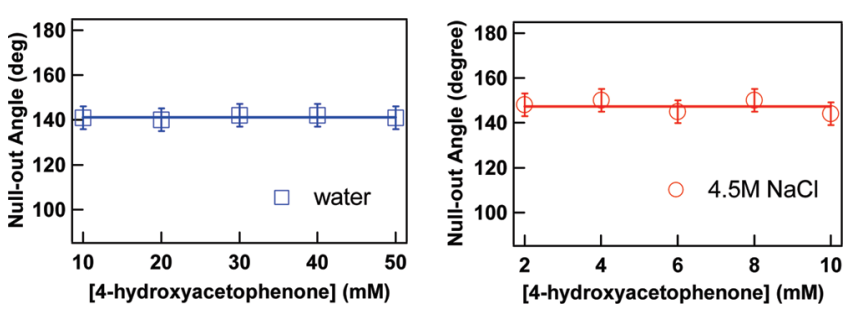

Figure 3. Null angles of SHG light for 4-hydroxyacetophenone in water $(\square)$ and $4.5 \mathrm{M} \mathrm{NaCl}(\bigcirc)$ at $18{ }^{\circ} \mathrm{C}$. signal (e.g., from interfacial water or $\mathrm{NaCl}$ ). The fitted $E_{0}$ values for water, $2.8 \mathrm{M} \mathrm{NaCl}$ and $4.5 \mathrm{M} \mathrm{NaCl}$ are $7.6 \pm 0.4,10.1 \pm$ 0.3 and $10.4 \pm 0.2$, respectively. These values are in close agreement with the observed SHG fields from the corresponding organic-free interfaces $(7.7 \pm 0.06,10.2 \pm 0.1$, and $10.5 \pm$ 0.07 respectively). The parameter $E_{\mathrm{SHG} \text { max }}$ represents limiting value of the SHG electric field of 4-HA and the fit results are $22 \pm 4,23 \pm 4$, and $15 \pm 1$ respectively for water, $2.8 \mathrm{M} \mathrm{NaCl}$, and $4.5 \mathrm{M} \mathrm{NaCl}$. Note these values are nearly twice the effective SHG field of 4-HA at the highest bulk concentration. The parameter $a$ yields the adsorption free energy according to eq 3. The calculated adsorption free energies are shown in Table 1. The results from the two techniques agree very well within the experimental accuracy. Das et al. found that the adsorption free energy of $p$-nitrophenol decreases from $-5.16 \pm 0.19 \mathrm{kcal}$ $\mathrm{mol}^{-1}$ in water to $-5.62 \pm 0.28 \mathrm{kcal} \mathrm{mol}^{-1}$ in $3 \mathrm{M} \mathrm{LiCl}^{30}$ The change in the adsorption free energy of $p$-nitrophenol by $3 \mathrm{M}$ $\mathrm{LiCl}\left(0.46 \mathrm{kcal} \mathrm{mol}^{-1}\right)$ is similar in magnitude to that of 4-HA by $2.8 \mathrm{M} \mathrm{NaCl}\left(0.4 \mathrm{kcal} \mathrm{mol}^{-1}\right)$. Richmond and co-workers ${ }^{40}$ reported different amounts of surface enhancement of hexanoic acid by $3 \mathrm{M} \mathrm{NaCl}$ (and $1 \mathrm{M} \mathrm{Na}_{2} \mathrm{SO}_{4}$ ) as determined by surface tension measurements and VSFG detection of the hexanoic acid $-\mathrm{C}=\mathrm{O}$ group. They attribute this observation to salt-induced reorientation of hexanoic acid. Salting-out drives more organic molecules from bulk to the interface. As a result, organic molecules become more densely packed at the interface and the intermolecular interaction between surface organic molecules may become stronger in the presence of salt. For $5 \mathrm{mM}$ hexanoic acid, the surface area per molecule ('footprint'), calculated from surface excess, decreases from $59 \AA^{2}$ in water to $44 \AA^{2}$ to in the presence of $3 \mathrm{M} \mathrm{NaCl}^{40}$ In the present study, for $10 \mathrm{mM}$ bulk 4-HA concentration the surface area per molecule is 260 $\AA^{2}, 93 \AA^{2}$, and $53 \AA^{2}$ respectively in pure water, $2.8 \mathrm{M} \mathrm{NaCl}$, and $4.5 \mathrm{M} \mathrm{NaCl}$. Although the packing density of 4-HA molecules increases with increasing $\mathrm{NaCl}$ concentration, we obtain good agreement between the results from SHG and surface tension measurements for 4-HA. This suggests that the intermolecular interaction between the surface 4-HA molecules does not change significantly in the presence of salt. Note that surface tension and SHG may probe different regions at the interface. $^{31,32}$ This leads to the possibility of discrepancy in the results from the two techniques. These effects may be predominant at higher solute concentrations because layers beyond the top monolayer layer may complicate the observation. ${ }^{31,32}$ The low solubility of 4-HA makes the probability of multiple layer formation at the interface small, consistent with the SHG and surface tension data. Furthermore, the Langmuir model applies to single-layer adsorption.

SHG experiments ${ }^{38}$ and MD simulations ${ }^{45}$ have shown that neither $\mathrm{Na}^{+}$nor $\mathrm{Cl}^{-}$has positive surface excess at the airsolution interface. VSFG experiments further imply that $\mathrm{NaCl}$ does not alter interfacial water structure. ${ }^{33,36,37}$ Thus, the higher surface affinity of the organic species at higher bulk salt concentration is not explained by any favorable interaction between the organic species and ions at the interface. This is further supported by the null-angle measurements of the SHG light, which indicate that the orientation of 4-HA at the air-saltsolution interface is similar to that in neat water. It is believed that $\mathrm{Na}^{+}$and $\mathrm{Cl}^{-}$ions are preferentially solvated by water and the organic molecules are expelled from their aqueous solvation shell. As a result, the adsorption free energy of the organic molecule to the interface decreases compared to that at the neat water interface. The direct manifestation of this salting-out phenomena is lowering of solubility of organic species in salt 
solution. ${ }^{15-19}$ In this case, the solubility of 4-hydroxyactophenone in $4.5 \mathrm{M} \mathrm{NaCl}(12.5 \mathrm{mM})$ is $\sim 6$ times lower than that in water $(\sim 75 \mathrm{mM})$.

Characterization of Salting-Out. The adsorption free energy is the difference of the free energy of the solute at the interface and in the bulk. It is well-known that $\mathrm{NaCl}$ increases the chemical potential of organic molecules in the bulk (saltingout). ${ }^{15-19} \mathrm{As} \mathrm{NaCl}$ does not reside at the interface, the chemical potential of the organic molecules at the interface is the same in the absence $\left(G_{0}^{\text {int }}\right)$ and in the presence $\left(G_{\mathrm{NaCl}}^{\mathrm{int}}\right)$ of salt. Hence, the difference between the adsorption free energy in the absence $\left(\Delta G_{\mathrm{ad}, 0}\right)$ and in the presence $\left(\Delta G_{\mathrm{ad}, \mathrm{NaCl}}\right)$ of salt is equal to the difference between the free energy of 4 -HA in the bulk in the absence $\left(G_{0}^{\text {bulk }}\right)$ and in the presence $\left(G_{\mathrm{NaCl}}^{\text {bulk }}\right)$ of salt: ${ }^{16,40}$

$$
\begin{aligned}
\Delta G_{\mathrm{ad}, 0}-\Delta G_{\mathrm{ad}, \mathrm{NaCl}}=\left(G_{0}^{\mathrm{int}}-G_{0}^{\mathrm{bulk}}\right) & -\left(G_{\mathrm{NaCl}}^{\mathrm{int}}-G_{\mathrm{NaCl}}^{\mathrm{bulk}}\right)= \\
& -\left(G_{0}^{\mathrm{bulk}}-G_{\mathrm{NaCl}}^{\mathrm{bulk}}\right)
\end{aligned}
$$

Garde and co-workers provide a direct relationship between the salt concentration $\left(C_{\mathrm{S}}\right)$ dependence of solute chemical potential change in the bulk and the Setschenow (salting-out) coefficient, $k_{\mathrm{s}}$, as: ${ }^{18}$

$$
k_{\mathrm{s}}=\frac{G_{\mathrm{NaCl}}^{\text {bulk }}-G_{0}^{\text {bulk }}}{2.303 R T C_{\mathrm{S}}}
$$

Using eqs 5 and 6, we get:

$$
k_{\mathrm{s}}=\frac{\Delta G_{\mathrm{ad}, \mathrm{NaCl}}-\Delta G_{\mathrm{ad}, 0}}{2.303 R T C_{\mathrm{S}}}
$$

The salting-out constants calculated using eq 7 and the free energies of adsorption from the experimental surface tension and SHG data are given in Table 1. The salting-out constant of 4-HA in $\mathrm{NaCl}$ is found to be very close to that of two structurally similar organics, $p$-nitrophenol $(0.165)$ and $o$-hydroxy benzoic acid (0.172). ${ }^{19}$ This agreement reinforces the concept that the salting-out effect of salt in the bulk is the controlling factor for the enrichment of organic molecules at the air-water interface.

\section{Conclusions}

This work demonstrates that $\mathrm{NaCl}$ significantly decreases the free energy of adsorption of 4-HA, a neutral organic molecule, to the air-water interface. The agreement between the surface tension and SHG results, along with the null out angle measurements, showed that the orientation and intermolecular interactions between surface 4-HA molecules do not vary significantly with salt or organic concentration. Thus, we conclude that the enrichment of 4-HA at the air-water interface is directly connected to the bulk salting-out effect. These results have implications for the surface-bulk partitioning of organic material in environmental systems such as aqueous atmospheric aerosols and the sea surface microlayer.

Acknowledgment. V.F.M. acknowledges the NASA Tropospheric Chemistry program (grant \#NNX09AF26G) for funding. K.B.E. acknowledges NSF Division of Chemistry, DOE Office of Basic Energy Sciences, and DTRA (grant \#W911NF-07-10116) for support.

\section{References and Notes}

(1) Finlayson-Pitts, B. J.; Pitts, J. N. Chemistry of the Upper and Lower Atmosphere: Theory, Experiments, and Applications, 1st ed.; Academic Press: San Diego, 2000.

(2) Kanakidou, M.; Seinfeld, J. H.; Pandis, S. N.; Barnes, I.; Dentener, F. J.; Facchini, M. C.; Van Dingenen, R.; Ervens, B.; Nenes, A.; Nielsen, C. J.; Swietlicki, E.; Putaud, J. P.; Balkanski, Y.; Fuzzi, S.; Horth, J.; Moortgat, G. K.; Winterhalter, R.; Myhre, C. E. L.; Tsigaridis, K.; Vignati,

E.; Stephanou, E. G.; Wilson, J. Atmos. Chem. Phys. 2005, 5, 1053.

(3) Seinfeld, J. H.; Pandis, S. N. Atmospheric Chemistry and Physics: From Air Pollution to Climate Change; Wiley: New York, 1998.

(4) Chuang, P. Y.; Charlson, R. J.; Seinfeld, J. H. Nature 1997, 390, 594.

(5) Ruehl, C. R.; Chuang, P. Y.; Nenes, A. Geophys. Res. Lett. 2009, 36, L15814.

(6) Garland, R. M.; Wise, M. E.; Beaver, M. R.; Dewitt, H. L.; Aiken,

A. C.; Jimenez, J. L.; Tolbert, M. A. Atmos. Chem. Phys. 2005, 5, 1951.

(7) Archer, R. J.; La Mer, V. K. J. Phys. Chem. 1955, 59, 200.

(8) Rosano, H. L.; La Mer, V. K. J. Phys. Chem. 1956, 60, 348.

(9) Feingold, G.; Chuang, P. Y. J. Atmos. Sci. 2002, 59, 2006.

(10) Kohler, H. Trans. Faraday Soc. 1936, 32, 1152.

(11) McNeill, V. F.; Patterson, J.; Wolfe, G. M.; Thornton, J. A. Atmos. Chem. Phys. 2006, 6, 1635.

(12) McNeill, V. F.; Wolfe, G. M.; Thornton, J. A. J. Phys. Chem. A 2007, 111, 1073

(13) Folkers, M.; Mentel, T. F.; Wahner, A. Geophys. Res. Lett. 2003, $30,1644$.

(14) Stemmler, K.; Vlasenko, A.; Guimbaud, C.; Ammann, M. Atmos. Chem. Phys. 2008, 8, 5127.

(15) Long, F. A.; McDevit, W. F. Chem. Rev. 1952, 51, 119.

(16) Aveyard, R.; Saleem, M. S. Can. J. Chem. 1977, 55, 4018.

(17) Schlautman, M. A.; Yim, S.; Carraway, E. R.; Lee, J. H.; Herbert,

B. E. Water Res. 2004, 38, 3331.

(18) Kalra, A.; Tugci, N.; Cramer, S. M.; Garde, S. J. Phys. Chem. B 2001, 105, 6380 .

(19) Xie, W. H.; Shiu, W. Y.; Mackay, D. A. Mar. Environ. Res. 1997, $44,429$.

(20) Goard, A. K.; Rideal, E. K. J. Chem. Soc. Trans. 1925, 127, 1668.

(21) Ozdemir, O.; Karakashev, S. I.; Nguyen, A. V.; Miller, J. D. Miner. Eng. 2009, 22, 263.

(22) Demou, E.; Donaldson, D. J. J. Phys. Chem. A 2002, 106, 982.

(23) Tuckermann, R.; Cammenga, H. K. Atmos. Environ. 2004, 38, 6135.

(24) Tuckermann, R. Atmos. Environ. 2007, 41, 6265.

(25) Hicks, J. M.; Kemnitz, K.; Eisenthal, K. B.; Heinz, T. F. J. Phys. Chem. 1986, 90, 560.

(26) Shen, Y. R. Аnпи. Rev. Phys. Chem. 1989, 40, 327.

(27) Eisenthal, K. B. Acc. Chem. Res. 1993, 26, 636.

(28) Heinz, T. F.; Tom, H. W. K.; Shen, Y. R. Phys. Rev. A 1983, 28 , 1883

(29) Zhang, W.; Wang, H.; Zheng, D. Phys. Chem. Chem. Phys. 2006, $8,4041$.

(30) Das, K.; Sarkar, N.; Das, S.; Datta, A.; Nath, D.; Bhattacharyya, K. J. Chem. Soc., Faraday Trans. 1996, 92, 4993.

(31) Shultz, M. J.; Baldelli, S.; Schnitzer, C.; Simonelli, D. J. Phys. Chem. B 2002, 106, 5313 .

(32) Shultz, M. J.; Schnitzer, C.; Simonelli, D.; Baldelli, S. Int. Rev. Phys. Chem. 2000, 19, 123.

(33) Schnitzer, C.; Baldelli, S.; Shultz, M. J. J. Phys. Chem. B 2000, 104, 585.

(34) Tarbuck, T. L.; Richmond, G. L. J. Am. Chem. Soc. 2006, 128, 3256.

(35) Allen, H. C.; Raymond, E. A.; Richmond, G. L. Curr. Opin. Colloid In. 2000, 5, 74.

(36) Raymond, E. A.; Richmond, G. L. J. Phys. Chem. B 2004, 108, 5051.

(37) Liu, D.; Ma, G.; Levering, L.; Allen, H. C. J. Phys. Chem. B 2004, 108, 2252.

(38) Bian, H.; Feng, R.; Xu, Y.; Guo, Y.; Wang, H. Phys. Chem. Chem. Phys. 2008, 10, 4920.

(39) Rao, Y.; Subir, M.; McArthur, E. A.; Turro, N. J.; Eisenthal, K. B. Chem. Phys. Lett. 2009, 477, 241.

(40) Soule, M. C. K.; Blower, P. G.; Richmond, G. L. J. Phys. Chem. B 2007, 111, 13703.

(41) Forstner, H. J. L.; Flagan, R. C.; Seinfeld, J. H. Environ. Sci. Technol. 1997, 31, 1345.

(42) Sadekov, I. D.; Minkin, V. I.; Lutskii, A. E. Russ. Chem. Rev. 1970, $39,179$.

(43) Eisenthal, K. B. Chem. Rev. 1996, 96, 1343.

(44) Adamson, A. W. Physical Chemistry of Surfaces, 5th ed.; Wiley: New York, 1990.

(45) Jungwirth, P.; Tobias, D. J. J. Phys. Chem. B 2002, 106, 6361.

JP1071742 